\title{
FUNDIÇÃO DE PRECISÃO PARA A PRODUÇÃO DE PEÇAS DE ZINCO COM GEOMETRIA COMPLEXA *
}

\author{
Raíra Morais Alcântara Nunes ${ }^{1}$ \\ Augusto Adolfo Salgado Neto ${ }^{2}$ \\ Francisco William PeresTeixeira Filho ${ }^{3}$ \\ Jeferson Leandro Klug ${ }^{4}$ \\ Péricles Mendes de Medeiros ${ }^{5}$ \\ Tito Lívio Lima de Oliveira ${ }^{6}$
}

\section{Resumo}

No laboratório de fundição da Universidade Federal do Ceará, foi desenvolvido novas técnicas de fundição de precisão visando reduzir os custos utilizando materiais reciclados, como sucatas e cinzas residuais de termoelétrica. Ademais, ocorreu a preparação das peças modelo, utilização de silicone para a produção de moldes, preparação das peças em cera e canais de vazamento, fabricação da casca cerâmica refratária, vazamento da liga metálica (ZAMAC), obtenção da peça rústica e processo de usinagem. Desse modo, concluímos nosso projeto dando utilidade para um material poluente e reciclando sucata de zinco e, por consequência, baixando os custos desse processo e podendo haver, também, a geração de emprego para comunidades carentes.

Palavras-chave: Fundição; Reciclagem; Zamac; Refratário.

\section{INVESTMENT CASTING FOR THE PRODUCTION OF ZINC PARTS WITH COMPLEX GEOMETRY}

\section{Abstract}

In the foundry laboratory of the UFC (Federal University of Ceará), new precision casting techniques were developed to reduce costs using recycled materials such as scrap and residual ashes from thermoelectric. In addition, the preparation of the model pieces, the use of silicone for the production of molds, preparation of the wax models and leakage channels, manufacture of the refractory ceramic cast, leakage of the metallic alloy (ZAMAC), obtaining the rustic part and the machining process. In this way, we conclude our project giving usefulness to a polluting material and recycling zinc scrap and, consequently, lowering the costs of this process and may also be the generation of employment for poor communities.

Keywords: Casting; Recycling; Zamac; Refractory.

1 Graduanda em Engenharia Metalúrgica e de Materiais, Universidade Federal do Ceará, Fortaleza, Ceará, Brasil.

2 Graduando em Engenharia Mecânica, Universidade Federal do Ceará, Fortaleza, Ceará, Brasil.

3 Graduando em Engenharia Metalúrgica e de Materiais, Universidade Federal do Ceará, Fortaleza, Ceará, Brasil.

4 Prof. Dr.-Ing., Universidade Federal do Ceará, Fortaleza, Ceará, Brasil.

5 Graduando em Engenharia Metalúrgica e de Materiais, Universidade Federal do Ceará, Fortaleza, Ceará, Brasil.

6 Graduando em Engenharia Mecânica, Universidade Federal do Ceará, Fortaleza, Ceará, Brasil. 


\section{INTRODUÇÃO}

Fundição é um processo pirometlúrgco de fabricação de peças metálicas que consiste em elevar a temperatura do metal a ponto de que ele chegue no estado líquido e assim, o mesmo é vazado em um molde refratário. Um dos métodos mais conhecidos é a fundição de precisão ou Investment Casting, que consiste em formar uma casca cerâmica refratária para ser utilizada como molde. Desse modo, obtémse um revestimento da peça desejada. Portanto, ocorre uma maior precisão no resultado final do processo, ou seja, podendo-se fabricar peças com nível elevado de detalhes. Num método mais artesanal a lama refratária é composta por areia, gesso e pó de tijolo aglomerados com água e manta acrílica. Essas composições são únicas, adaptando às preferências de cada fabricante. Embora o processo artesanal já seja de baixo custo, ainda são válidas alternativas que barateiem ainda mais esse método, visto que ele é utilizado por pequenos empresários ou produtores autônomos.

No método a ser pesquisado, foi utilizado um resíduo da termoelétrica, cinza volante, aplicada à lama refratária substituindo o pó de tijolo. Tal substituição foi aplicada, visto que os materiais possuem granulometria semelhante e alto ponto de fusão. A vantagem de se utilizar a cinza volante nesse processo é que, atualmente, ela não possui nenhum uso comercial, sendo descartada no meio ambiente como poluente.

\section{MATERIAIS E MÉTODOS}

\subsection{Preparação das peças modelo}

Primeiramente, ocorreu a escolha das peças que iriam ser reproduzidas. Escolheram-se peças de xadrez em madeira, visto que as mesmas possuem geometria complexa e detalhada. Desse modo, as peças foram pinceladas com vaselina sólida e coladas no fundo de copos descartáveis para que possa ser feito o molde em silicone. Assim, a vaselina ajudará no desmolde e o copo lhe dará estrutura.

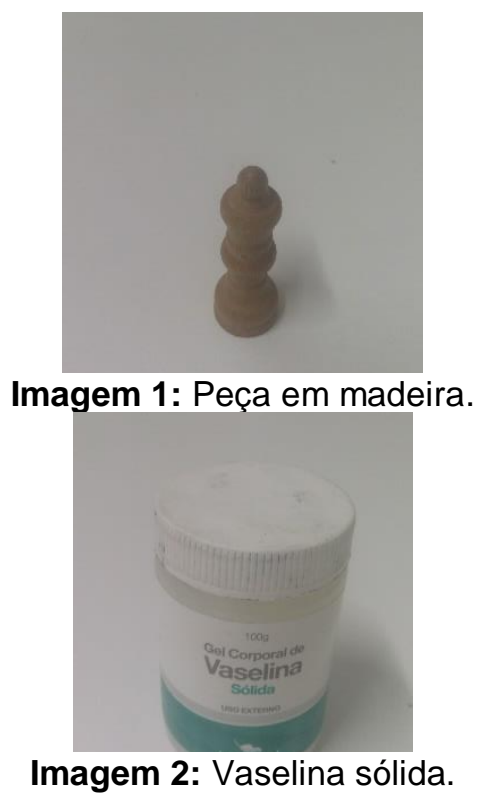




\subsection{Preparação do silicone para a produção dos moldes}

O silicone utilizado é encontrado em lojas de artesanato e, o mesmo, acompanha um catalisador, o qual serve para solidificar o silicone. As proporções de catalisador e silicone são fornecidas pelo fabricante, sendo para cada $1000 \mathrm{~g}$ de silicone é necessário $30 \mathrm{~g}$ de catalisador. Portanto, utilizou-se uma balança de precisão para manter a proporção necessária. Desse modo, a mistura foi vazada no copo com a peça modelo. Ao final da solidificação (24 horas de descanso), é feita a desmoldagem e obtém-se um molde fêmea com o formato da peça modelo a ser replicada. Vale ressaltar, que a vida útil do molde de silicone é de aproximadamente trinta dias de uso contínuo.

Imagem 3: Silicone industrial.

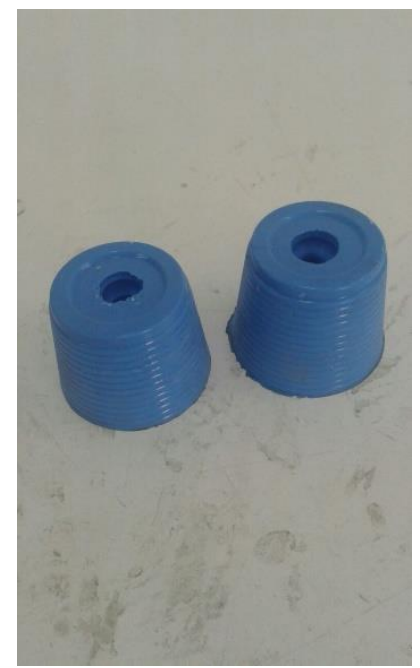

Imagem 4: Molde de silicone.

\subsection{Preparação das peças em cera e dos canais de vazamento}

Para esse estudo, foi-se utilizada uma cera parafínica doada pelo Laboratório de Cerâmicas Avançadas da universidade, a mesma foi fundida na estufa a $150^{\circ} \mathrm{C}$ e vazada no molde fêmea de silicone. Depois de 30 minutos de descanso, a peça em cera foi desmoldada sem a destruição do molde. Entretanto, somente a peça não é suficiente para esse processo, também é necessário um canal de vazamento, feito do mesmo material, para que o metal possa alcançar a peça mesmo depois de revestida pela casca cerâmica. Tal canal foi soldado à base do modelo. 


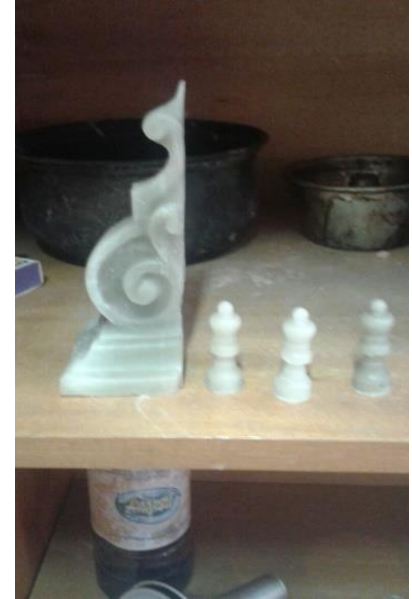

Imagem 5: Peças em cera.

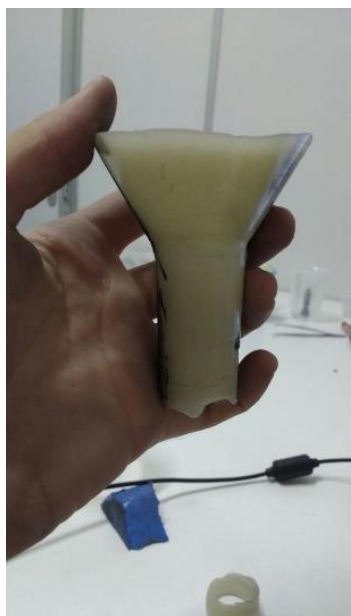

Imagem 6: Canal de vazamento.

\subsection{Preparação da casca cerâmica refratária}

A produção da lama refratária foi baseada numa fundição artesanal do interior de Minas Gerais. Sua composição original consistia de areia, pó de tijolo, gesso, manta acrílica e água. Visando reduzir os custos desse processo e dar uma utilidade a um material poluente, a cinza volante de termoelétrica foi integrada à composição da lama. Assim, novas composições foram pesquisadas e tiveram seus resultados comparados.

\subsection{Preparação do molde final}

A peça em cera é revestida com a lama refratária, assim que ela seca obtém-se um molde maciço úmido. Esse molde é secado em uma estufa, onde há a retirada da cera. Em seguida, ele vai ao forno para ser calcinado, esse processo lhe dá mais resistência mecânica. Nesse ponto ele está pronto para receber o metal fundido. 


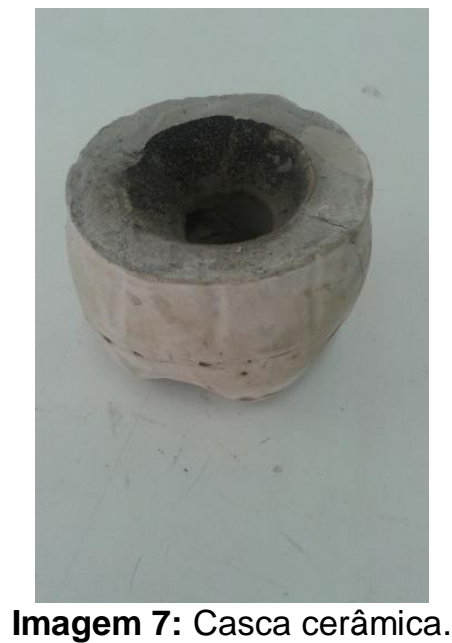

\subsection{Vazamento da liga metálica}

Ainda com o intuito de fazer um processo de baixo custo, foi feito um forno artesanal com areia e gesso em um balde de aço. A esse forno foi adicionado uma entrada de ar e um secador de cabelo foi utilizado parar gerar uma circulação de ar dentro de forno. Além disso, um copo de aço foi utilizado como cadinho e carvão vegetal comercial foi usado como combustível. Depois do fogo aceso, a carga era introduzida no cadinho e fundida em questão de minutos. Para essa pesquisa foi usada Zamac, uma liga de zinco, visto que ela possui baixo ponto de fusão, é facilmente reciclada e tem um bom acabamento.

\section{RESULTADOS E DISCUSSÃO}

\subsection{Preparação das amostras}

Para obter diferentes resultados, foram testados diversos processos e composições da lama refratária. Cada material da lama possui uma função específica, a areia dá resistência térmica e mecânica, o gesso contribui na moldagem do material e o pó de tijolo ajudará com a precisão do acabamento final, visto que possui uma granulometria muito pequena. Em todos os testes subsequentes a cinza volante substitui o pó de tijolo, pois ambos possuem propriedades físicas semelhantes. A fundição artesanal que inspirou esse trabalho consistia em uma proporção de onze partes em volume de areia, mais seis partes em volume de gesso, mais uma parte e meia em volume de pó de tijolo, mais manta acrílica e água para aglomerar. A partir disso, os testes foram feitos com o intuito de reproduzir tal prática, assim decidiu-se fazer uma lama com partes iguais de gesso, areia e cinza volante, água e um grama de manta acrílica. Alternativamente, pela cinza já ter elevado ponto de fusão, também foi estudado a possibilidade de não utilizar areia, assim a casca seria composta apenas por cinza volante e gesso. Nesse último caso, a manta acrílica também foi desconsiderada sob a hipótese de que a água deveria ser aglomerante suficiente para a nova mistura.

Tabela 1. Proporções em volumes das amostras

\begin{tabular}{ccccc}
\hline Amostras & Areia & Gesso & Cinza Volante & Água \\
\hline Amostra 1 & 1 & 1 & 1 & $0,7-1$ \\
\hline
\end{tabular}


Vale ressaltar que, independente da mistura da lama que for produzida, precisa-se passar por algumas etapas antes do vazamento do metal: secagem e calcinação. A secagem consiste na retirada de cera e a umidade do molde. Em seguida, a calcinação dará a peça mais resistência mecânica. Como a quantidade de água não era calculada com precisão e nem sempre foi usada uma quantidade fixa, o tempo de secagem necessário era diferente para cada peça. Entretanto, usando um tempo aproximado e suficiente para a retirada da cera, o resto da umidade é retirada durante a calcinação sem interferir no ganho de resistência mecânica. Portanto, para a secagem, as peças foram submetidas à $200^{\circ} \mathrm{C}$ por duas horas, e a aproximadamente $400^{\circ} \mathrm{C}$ por quatro horas para a calcinação.

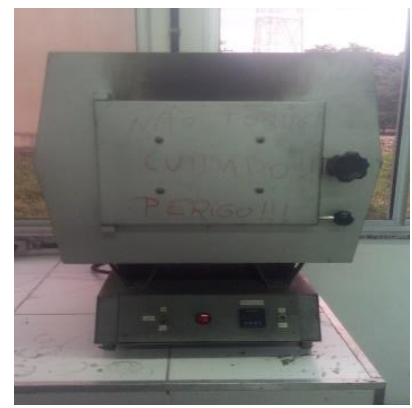

Imagem 8: Forno elétrico.

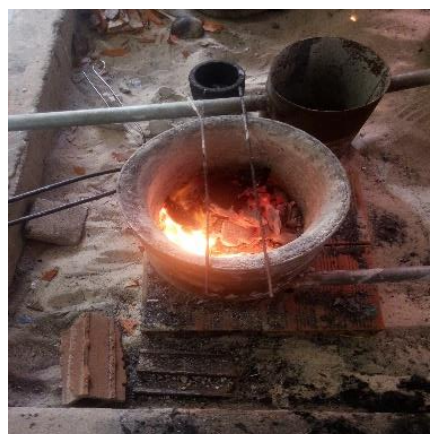

Imagem 9: Forno artesanal.

Segue abaixo a tabela da composição química da cinza volante de termoelétrica. Diferentemente de outros tipos de cinza, a mesma apresenta óxido de enxofre, o que dificulta a reciclagem com outros fins, como por exemplo, a produção de cerâmicas. O óxido de enxofre representa um risco à estrutura de qualquer cerâmica, pois ele tende a expandir e contrair muito facilmente. Desse modo, seu uso pode ser justificado na fabricação de moldes, visto que eles serão usados apenas uma única vez, ou seja, problemas que surgiriam a longo prazo se tornam irrelevantes.

Tabela 2. Análise química da cinza

\begin{tabular}{lclllc}
\hline Analyte & Result & $\begin{array}{l}\text { Proc- } \\
\text { Calc }\end{array}$ & Line & Net Int. & BG Int. \\
\hline $\mathrm{SiO}_{2}$ & $57,9787 \%$ & $\begin{array}{l}\text { Quant.- } \\
\text { FP }\end{array}$ & SiKa & 256.623 & 1.072 \\
& & & & \\
& & & &
\end{tabular}




\begin{tabular}{|c|c|c|c|c|c|}
\hline \multicolumn{2}{|c|}{$\begin{array}{l}\mathbf{1 7}^{\circ} \text { Enemet } \\
\text { Anais do Enemet - Encontro Nacional de Estudantes de } \\
\text { Engenharia Metalúrgica, de Materiais e de Minas }\end{array}$} & ISSN 2594-471 & \multicolumn{2}{|c|}{ vol. 17, num. 1 (2017) } & $\begin{array}{l}\text { abon } \\
\text { Weit }\end{array}$ \\
\hline $\mathrm{Al}_{2} \mathrm{O}_{3}$ & $15.0274 \%$ & $\begin{array}{l}\text { Quant.- } \\
\text { FP }\end{array}$ & AlKa & 92.774 & 5.293 \\
\hline $\mathrm{Fe}_{2} \mathrm{O}_{3}$ & $9.3193 \%$ & $\begin{array}{l}\text { Quant.- } \\
\text { FP }\end{array}$ & FeKa & 188.481 & 1.607 \\
\hline $\mathrm{CaO}$ & $3.4681 \%$ & $\begin{array}{l}\text { Quant.- } \\
\text { FP }\end{array}$ & CaKa & 44.091 & 0.789 \\
\hline $\mathrm{SO}_{3}$ & $2.6448 \%$ & $\begin{array}{l}\text { Quant.- } \\
\text { FP }\end{array}$ & $\mathrm{S} \mathrm{Ka}$ & 13.965 & 0.454 \\
\hline $\mathrm{K}_{2} \mathrm{O}$ & $2.4849 \%$ & $\begin{array}{l}\text { Quant.- } \\
\text { FP }\end{array}$ & $\mathrm{K} \mathrm{Ka}$ & 42.354 & 0.936 \\
\hline $\mathrm{TiO}_{2}$ & $1.0301 \%$ & $\begin{array}{l}\text { Quant.- } \\
\text { FP }\end{array}$ & TiKa & 4.003 & 0.276 \\
\hline $\mathrm{CO}_{2}$ & $6.4400 \%$ & $\begin{array}{l}\text { Quant.- } \\
\text { FP }\end{array}$ & - & - & - \\
\hline
\end{tabular}

\subsection{Obtenção da peça metálica rústica e processo de usinagem}

Após o processo de secagem e calcinação da casca cerâmica, a liga metálica Zamac foi fundida no forno artesanal (2.6) e vazada, delicadamente, na casca cerâmica. Após 30 minutos de descanso, a casca é quebrada e é retirada peça rústica. Apesar do alto nível de detalhes, as peças rústicas possuem defeitos como gotas frias e inclusões. Para corrigir esses defeitos realiza-se uma pequena usinagem com uma mini retífica.

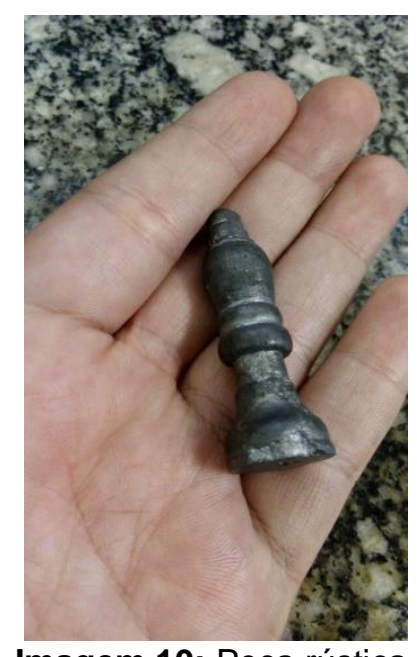

Imagem 10: Peça rústica. 


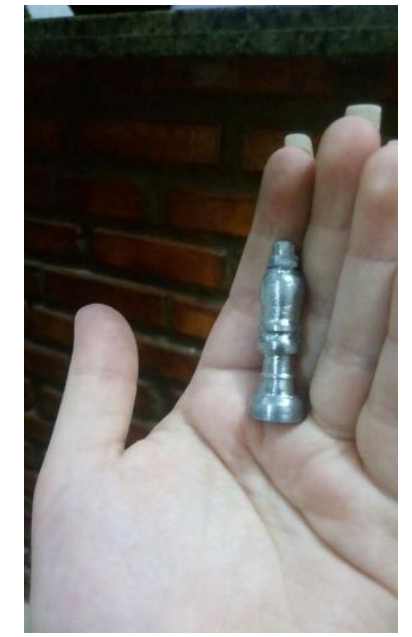

Imagem 11: Peça usinada

\section{CONCLUSÃO}

Portanto, depois de meses de pesquisa, foi possível desenvolver um processo de fundição de precisão com um produto final de qualidade, barato, e, além disso, foi dada utilidade a um material poluente, a cinza volante, proveniente de termoelétrica. Adamais, tal processo também poderá ser usado como fonte de renda para pequenos empreendedores iniciantes, visto que o processo utilizado tem várias etapas artesanais e com o custo ínfimo.

\section{Agradecimentos}

Para esse projeto, recebemos a colaboração do Professor Orientador Jeferson Leandro Klug, do Professor Ricardo Emílio Nogueira do Laboratório de Cerâmicas Avançadas e da equipe do curso de Design.

\section{REFERÊNCIAS}

1 CALLISTER, W. D., Ciência e Engenharia de Materiais: Uma Introdução. John Wiley \& Sons, Inc., 2002.

2 FERREIRA, José M. G. de Carvalho: Tecnologia da fundição, 3. ed. Lisboa: Fundação Calouste Gulbenkian, 2010.

3 SENAI - DEPARTAMENTO REGIONAL DE MINAS GERAIS. Areias de fundição aglomeradas com argila. 2. ed. Belo Horizonte: SENAI/MG, 1987. 4 v.

4 SENAI - DEPARTAMENTO REGIONAL DE MINAS GERAIS. Defeitos de fundição. 2. ed. Belo Horizonte: SENAI/MG, 1987. 134 p. (Publicação técnica) ;Fundição. 